\title{
Gender-based Game Engagement Model Validation using Low Fidelity Prototype
}

\author{
Shahryan Abdulrahman Alserri, Nor Azan Mat Zin, Tengku Siti Meriam Tengku Wook
}

\begin{abstract}
Lack of female involvement in ICT field calls for new approaches to ICT education. Serious game is an effective tool for learning, so it can be used to motivate and engage female students to study Computing. Engagement elements for serious game were identified from previous researches and a conceptual model for gender-based engagement using serious game was constructed. In this paper, the model validation of a low fidelity prototype using heuristic evaluation technique for educational game is discussed. The heuristic scale was adapted from previous studies, comprise of playability and enjoyment constructs. In addition, educational elements items are also included. The scale was then validated for content validity, and a pilot study with four (5) HCI experts. Finally, five (5) experts from HCI, Game and Computer Networking subject evaluate the model using this scale. Results of the evaluation showed that the model's constructs have good usability, playability, enjoyment. Future work will be to validate the model using high fidelity working prototype and user testing.
\end{abstract}

Keywords: Heuristic evaluation; serious games; game interface evaluation; game design.

\section{INTRODUCTION}

$\mathrm{T}$ here is a lack of female enrolment in Science, Technology, Engineering, Math (STEM) courses in higher education [1]-[8] such as Computer technologies (CT) courses. The number of women graduating from STEM courses is lesser than men, but they achieve higher average success and performance [9]. STEM careers are increasing faster than any other field [8], The related jobs offer very good remunerations because the STEM field is essential in advancing the benefits of the Fourth Industrial Revolution (4IR), including improvements in medical care, access to education, and the highest quality of living [7]. To increase the number of female enrolment in ICT, there is a need to increase female engagement with computing subjects. One approach is to use effective technological tools to motivate and engage female students, such as using serious games [10].

Revised Manuscript Received on April 25, 2020.

* Correspondence Author

Shahryan Abdulrahman Alserri*, Faculty of Information Science and Technology, Universiti Kebangsaan Malaysia, Selangor , Malaysia

Nor Azan Mat Zin, Faculty of Information Science and Technology, Universiti Kebangsaan Malaysia, Selangor, Malaysia

Tengku Siti Meriam Tengku Wook, Faculty of Information Science and Technology, Universiti Kebangsaan Malaysia, Selangor , Malaysia

(C) The Authors. Published by Blue Eyes Intelligence Engineering and Sciences Publication (BEIESP). This is an open access article under the CC BY-NC-ND license (http://creativecommons.org/licenses/by-nc-nd/4.0/)
Serious games are important technological applications used to educate, engage learners, and teach players [11]. Moreover, there is growing evidence that games can be used to motivate players to explore and engage in CS and digital knowledge [3]. Some studies have indicated that digital games could facilitate easier access to study and work in STEM fields [12]. On the other hand, many researches have indicated that the motivation to play specific kinds of games is based on gender preferences [13]-[19]. This is because men and women seem to have different motivations to play games [18]-[22]. Males and females also have different game engagement factors [17], different styles of play [14], [17], different learning styles [1], and different types of game preferences [13]. Moreover, the nature of their gameplay also differs [20]. For most of the game industry's history, few have made any effort to design games especially for girls or tried to guess the diversities of games that females would like [14], [21], [22]. Also, most educational games with CS subject are not interesting to girls teenagers [23], [24].

Hence, we studied gender-based engagement factors for serious games, which takes into consideration female preferences for digital games [25]. Then we construct a conceptual model to guide the game's design and development [2]. The resulting model incorporated learning, female preferences, and flow state theory elements and elaborated further in the next section. Subsequently, a low fidelity prototype was developed to validate the model using heuristic evaluation, for playability and enjoyment.

\section{A. Gender-Based Engagement Model for Serious Games (GBEM)}

GBEM consists of five components and 20 elements [2], [25]. We have refined the model. The element learning objective is part of pedagogy, therefore, is represented by pedagogy element. The second component is females' preferences, which had ten elements - explore, character customization, storyline, social interaction, collaboration, challenge, fun, feedback, and control. However, collaboration and social interaction concepts are similar, hence collaboration element is removed. The third component is female's preferences game's genre, which had two elements- role-play game, and fantasy. Role-play game element belongs to game genre, hence it is removed from Female Game element preferences component. Fantasy is female's preferences element for digital games, so it is removed from female preferred game genre component. The other female preferences elements are game storyline, challenges, fun, control and feedback.

Published By:

Blue Eyes Intelligence Engineering

Retrieval Number: D9042049420/2020@BEIESP

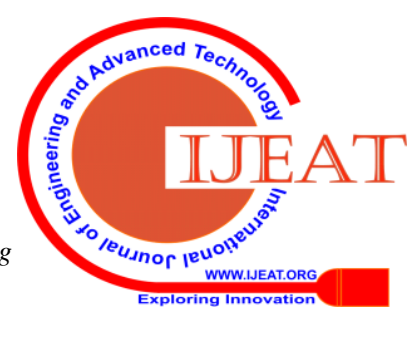


The fourth component is flow states theory elements concentration, clear goal, skill, and immersion. The final, refined model has three components with 15 elements: learning elements (1), females preferences elements (9), and flow state theory elements (4). These three components when applied to game design are expected to result in female engagement with the game and hence effectiveness of the serious game to motivate learners to study computing courses.

This refined model is then used to design a low fidelity prototype, and Heuristic evaluation is carried out on the prototype using Playability and Enjoyment Heuristics.

\section{B. Heuristic Evaluation}

Heuristic evaluation (HE) is one of the inspection methods used to analyse productivity software [26]. In usability analysis, using between three to five experts is recommended for heuristic evaluation since five evaluators are sufficient to identify most issues in usability [26]. HE has many advantages such as being cheap, intuitive, does not force advanced planning, and is easy to inspire people to take up [26]. A heuristic evaluation can be used in both the design and development processes [27], [28], where it can help to motivate a creative player experience [27]. General usability measurement method in game evaluation is inadequate since applications or systems are different compared to games [29]. Some researchers believe that video games need their own heuristics [29], [30]. Therefore many heuristics for video games have been developed [30]-[34].

Federoff (2002) created the first heuristic for video game by collecting a set of heuristics for games from a case study then she evaluated them with both Nielsen's heuristic and recent game industry guidelines [30]. The outcome is 40 heuristics categorized into three sets [30]. Federoff's heuristics suffer from shortage of clarity [33], consistency, and lack of validation [30]. Moreover, Federoff heuristics have difficulties to be used during the design phase [30], [33].

Another video games' heuristic is the Playability Heuristic evaluation (PLAY), which has three constructs [35]. This heuristic is expected for three types of digital games: the first-person shooter, real strategy, and action adventure [34]. Desurvire and Wiberg in (2009) constructed their heuristics based on a case study with low generality. Moreover, PLAY heuristics lack consistency and clarity [30]. Also, some game play heuristics in PLAY are not suitable for all game types, because each game type has its features, form, and usages that should be followed to develop an effective game [33].

In general, there is a list of heuristics elements used to evaluate any software that concentrates on user interface and interaction factors, but no specific heuristic has all the factors in an educational computer game (ECG) [33]. Factors like educational design and content should be considered in the assessment, so there is a need to develop heuristics that focus on ECG [36].

\section{Heuristic Evaluation of Educational Games}

Malone created the first Heuristic for educational game in the 1980s [37]. However, these heuristics need to identify playability concerns [38]. Malone's heuristics focused on what makes the games fun, but forgot to point out what makes games educational [39].
Omar, H., Yusoff, R, and Jaafar (2012) developed a heuristic evaluation instrument for educational computer games. Playability Heuristic Evaluation for Educational Game (PHEG) has five constructs; the interface, educational elements, content, Playability, and Multimedia [40]. Interface refers to the features of the application interface. Educational factors are the features that simplify learning. Content refers to game educational content delivered through the prototype. Playability means the game has gameplay factors.

On the other hand, enjoyment game flow (EGame Flow) by $\mathrm{Fu}$ et al. (2009) was introduced to evaluate enjoyment in serious games. EGameFlow consists of 8 constructs; immersion, autonomy, concentration, goal clarity, challenge, feedback, knowledge improvement, and social interaction [41].

Enjoyment is an essential element to maintain the quality of a game, and the more a player becomes engaged in the game, the higher is the game enjoyment and thus the engagement [39]. To evaluate the enjoyment of a game, it is essential to ascertain whether or not the game captures the player's attention [39] and concentration. Additionally, some researchers found a powerful connection between learning and flow in serious games [42]. Furthermore, flow has a good influence on engagement [39], [42]. Our model includes flow state theory and engagement elements. Thus EGameFlow is also suitable to be used to evaluate GBEM.

\section{MATERIALS AND METHOD}

Fig. 1 illustrates this research process flow, starting with designing the low fidelity prototype based on the game model. Next step is creating HE questionnaire by adapting from previous researches. Once the questionnaire is validated, the evaluation was carried out and results obtained are reported in the following section.

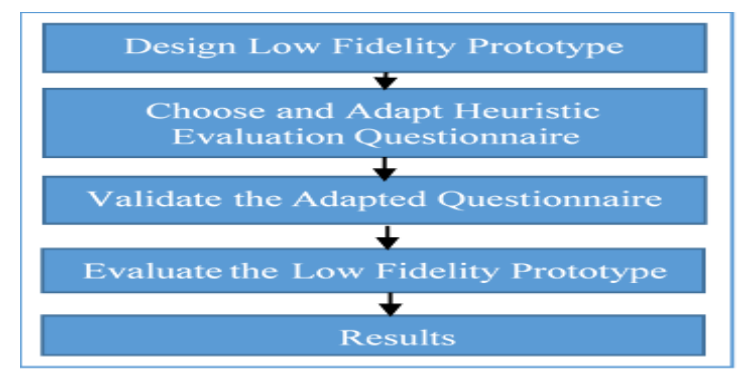

Fig. 1. Research Process Flow

\section{A. Designing Low Fidelity Prototype}

The design of the low fidelity prototype is based on the design model and is shown in Fig. 2. The goal of the game is to construct a Wired Local Area Network for a small office in a company. The interface language of the low fidelity prototype is Arabic because the target sample for the final game prototype is Arab female students. The game content is adapted from the "Construct Local Area Network" course for first-year students in a college in the Republic of Yemen.

Published By:

Blue Eyes Intelligence Engineering

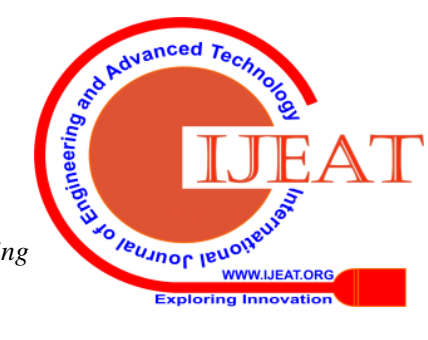


The prototype is designed as a role-playing game (RPG), where a player has to play the game character's role, centered on narrative acting.

The game story is created to make the game more immersive for players. The story theme is based on real-life experience of females in Arab society and culture; it is about life problems that females usually face in their patriarchal society community, university, and working life.

LANG consists of two levels. Each level has three tasks. Level 1, the game player has three (3) missions, which are

- To install an NIC (Network Identification Card) for all the office PCs.

- To choose an appropriate network device to connect the office PCs.

- To choose a suitable cable to connect the network device and all the office PCs.

In Level 2, the player has three (3) tasks:

- To connect the office LAN (Local AREA Network) with the office Internet, where the player has to choose the Internet device (router).

- The network server for the office LAN.

- To connect the office LAN with a server printer.

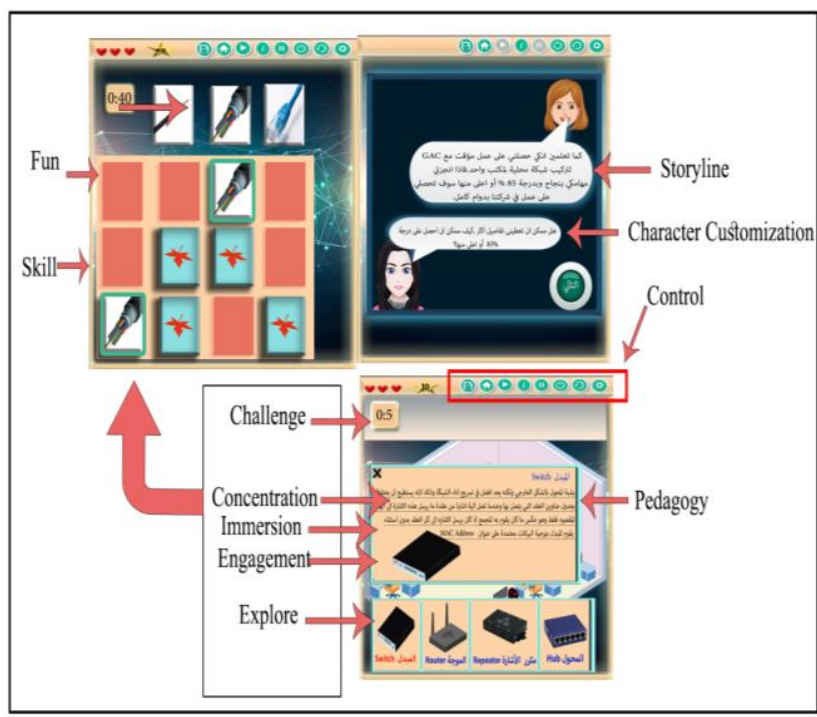

Fig. 2.Example of the low fidelity prototype interface design

\section{B. Instrument}

An adapted questionnaire is the instrument scale for this study. Four components from PHEG are adapted for this study. The components are Interface (IN) (5 items), Educational Element (ED) (3 items), Content (CN) (3 items), and Game Play (PL) (5 items).

Interface (IN) refers to the features of the application's interface.

Educational elements (ED) mean the features that simplify learning. Content (CN) refers to game educational content delivered through the prototype. Playability (PL) means the game has gameplay elements.

Two elements from the PLAY are adapted - emotional connection and story immersion. Emotional connection relates to the emotional relationship between the players and their avatar, whereas game story immersion relates to game story quality that is designed to make players immersed in the game.

Finally, 22 items are adapted from EGameFlow to measure digital game enjoyment [43]. The 22 items are adapted for use in our HE questionnaire since the items relate to and can measure elements of the game model of this study. All constructs and their items is shown in table I.

The HE questionnaire contains first, the demographic information such as expert's name, current position, institution, and years of experience. Second, it contains the items for expert evaluation of the low fidelity prototype.

\section{Instrument Validation}

The internal consistency using Cronbach's alpha and content validity were used in this study to check the questionnaire reliability and validity since the items of the questionnaire were adapted from earlier questionnaires.

Content validity: In the content validity, three to five experts is recommended for heuristic evaluation since five evaluators are enough to identify most usability issues, whereas adding more evaluators would decrease the benefit-to-cost ratio [26]. Based on that, in this study, four experts checked the content validity of the questionnaire. All experts are Human-Computer Interaction (HCI) experts. The experts' comments agree that the questionnaire items are indeed related to the model constructs. Hence the questionnaire is valid for further use to evaluate the model. Then, a pilot test was carried out to measure the reliability of the questionnaire using a sample of undergraduate female students.

- Pilot Study: Thirty-three (33) undergraduate female students from a local university's faculty of Information Science and Technology, were selected for the pilot study. The students answered the questionnaire in fifteen minutes. The results show that the Cronbach's alpha value of the questionnaire constructs is 0.918 , which means that the questionnaire is reliable and can, therefore, be used for evaluating the low-fidelity prototype. Heuristic evaluation was used to validate the low-fidelity prototype.

\section{Participants for Heuristic Evaluation}

Expert evaluation is a popular method in usability testing [26]. Five expert evaluators were invited to evaluate the low fidelity prototype in this study.

A purposive sampling method was used to choose the expert sample. Purposive sampling is used when a study needs to acquire knowledge from people that have specific experience [46].

Two experts are from Human Computer Interaction (HCI) field, one expert on educational content (Computer Networking), one game expert (a game developer), and one is a gamer. The experts were selected based on a minimum of five years of experience.

\section{Procedure}

First, the experts were given an invitation letter to be part of the evaluation team for the low fidelity prototype in this study.

Published By:

Blue Eyes Intelligence Engineering

Retrieval Number: D9042049420/2020@BEIESP

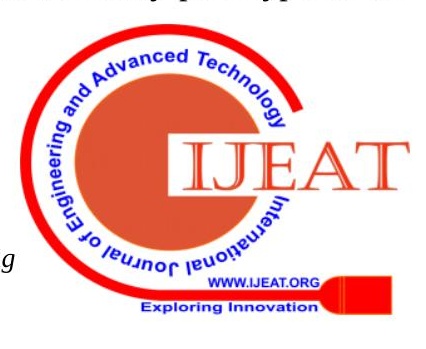


Then the experts were asked toset a convenient time for the evaluation task, which requires about thirty minutes.

Paper-Based interface design was given to the experts with description of the entire game progress, from the game's beginning to end. After that, the experts were given a questionnaire to evaluate the game based on the low fidelity prototype.

Video and audio recordings were used during the evaluation for evidence purposes.

Table- I: The Adapted Constructs and Elements of HE Questionnaire

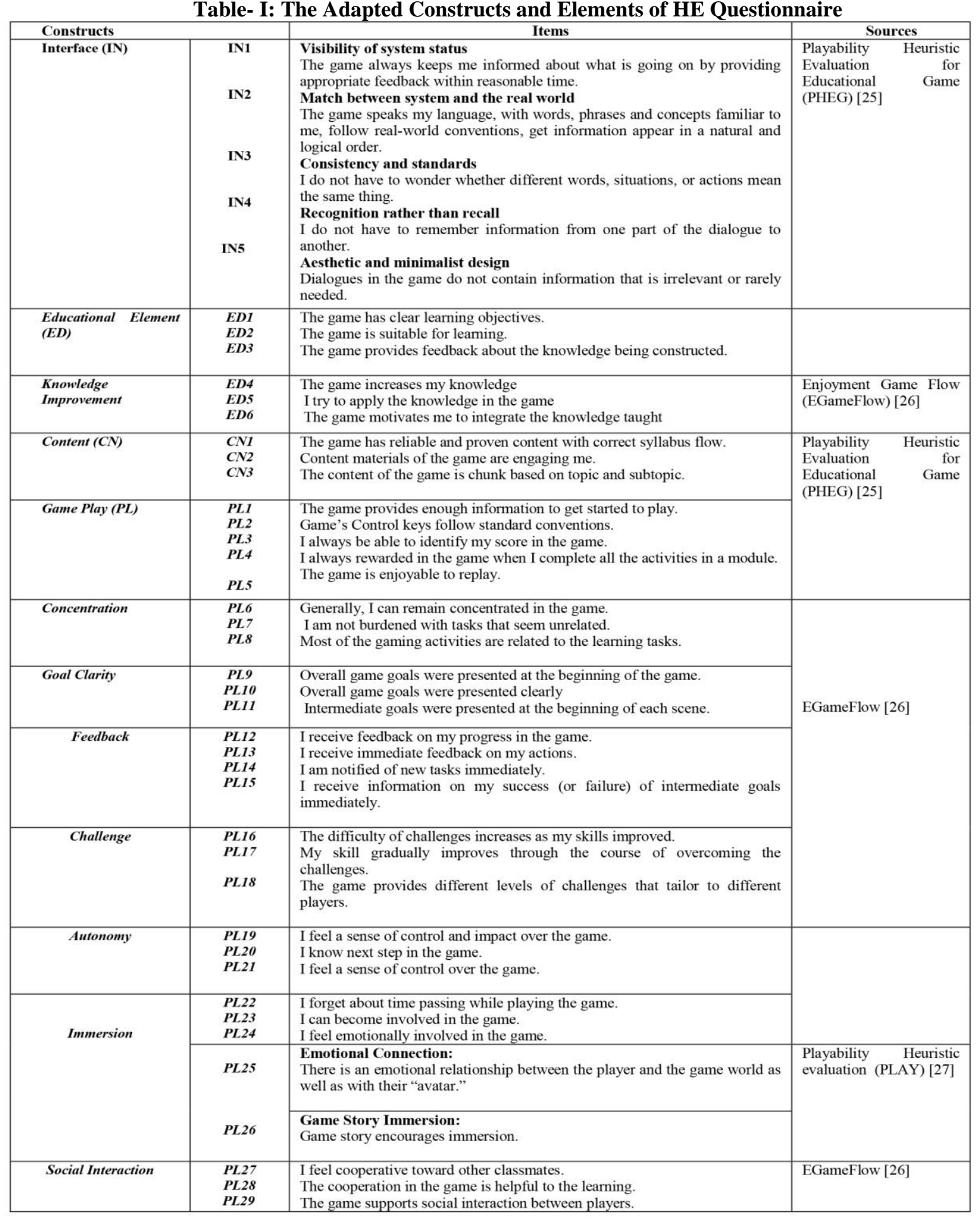

\section{RESUltS AND DISCUSSION}

In this section, the result from the HE is presented and discussed together with the experts' feedback. Table 2. Shows the percentage score results from the data analysis.

\section{Data analysis}

We used descriptive analysis technique to analyse the results of the $\mathrm{HE}$ questionnaire. The $\mathrm{HE}$ questionnaire consists of 4 components and 43 elements. The individual's agreement or otherwise for every element was evaluated in terms of "Yes", "No", or "Not sure". Next, the frequency rates were calculated. "Not sure" refers to any possibility that the expert is not sure about the answer to the statement/item.

Each of the experts responded with either "Yes", "No" or "Not sure" towards the low fidelity prototype interface design. 
Table-II: Low Fidelity Prototype Heuristic Evaluation Results

\begin{tabular}{|c|c|c|c|c|}
\hline Component & Item & Yes & No & Not sure \\
\hline \multirow{5}{*}{ IN } & IN1 & 100 & & \\
\hline & IN2 & 80 & 20 & \\
\hline & IN3 & 100 & & \\
\hline & IN4 & 100 & & \\
\hline & IN5 & 80 & 20 & \\
\hline \multirow{6}{*}{ ED } & ED1 & 100 & & \\
\hline & ED2 & 100 & & \\
\hline & ED3 & 100 & & \\
\hline & ED4 & 100 & & \\
\hline & ED5 & 100 & & \\
\hline & ED6 & 100 & & \\
\hline \multirow{3}{*}{$\mathrm{CN}$} & CN1 & 100 & & \\
\hline & CN2 & 100 & & \\
\hline & CN3 & 100 & & \\
\hline \multirow{13}{*}{ PL } & PL1 & 100 & & \\
\hline & PL2 & 80 & & 20 \\
\hline & PL3 & 100 & & \\
\hline & PL4 & 80 & 20 & \\
\hline & PL5 & 100 & & \\
\hline & PL6 & 100 & & \\
\hline & PL7 & 100 & & \\
\hline & PL8 & 100 & & \\
\hline & PL9 & 100 & & \\
\hline & PL10 & 100 & & \\
\hline & PL11 & 100 & & \\
\hline & PL12 & 100 & & \\
\hline & PL13 & 100 & & \\
\hline \multirow{16}{*}{ PL } & PL14 & 100 & & \\
\hline & PL15 & 100 & & \\
\hline & PL16 & 100 & & \\
\hline & PL17 & 100 & & \\
\hline & PL18 & 100 & & \\
\hline & PL19 & 100 & & \\
\hline & PL20 & 100 & & \\
\hline & PL21 & 80 & 20 & \\
\hline & PL22 & 100 & & \\
\hline & PL23 & 100 & & \\
\hline & PL24 & 80 & & 20 \\
\hline & PL25 & 100 & & \\
\hline & PL26 & & & 20 \\
\hline & PL27 & 100 & & \\
\hline & PL28 & 100 & & \\
\hline & PL29 & 100 & & \\
\hline
\end{tabular}

Most of the HE elements scored an average of $100 \%$, although a few scored $80 \%$. In terms of the Interface (IN), as shown in table III, the elements (IN1, IN3, and IN4) four experts agreed $100 \%$ that these elements have no usability problem.

However, one expert responded with "No" to two elements of the Interface (IN2, and IN5). Therefore, the low fidelity prototype interface design have no usability issues. In term of educational component (ED), all five experts agreed that all the elements (ED1, ED2, ED3, ED4, and ED5) in the game interface design supported educational elements.

Regarding game content (CN) elements (CN1, CN2, and CN3), all the evaluators agreed that the game design contents supported the learning subject -Computer Networking Subject curriculum.

Game Play (PL) component has 29 elements. The experts agreed that 24 elements of the game play (PL1..PL3, PL5..PL20, PL22, PL23, PL25, and PL27..PL29) are applicable and effective elements with a score of $100 \%$, while three elements of the game play (PL2, PL24, and PL26) received "Not Sure" and two game play elements (PL4,PL21) received a "No" from one expert. The feedback and comments for the expert, who answered with "No" have been taken into consideration. The scores of the four constructs of the game play (IN, ED, CN, and PL) were $80 \%$.

Table-III: Low Fidelity Prototype HE Results Based On Items

\begin{tabular}{|l|l|l|l|}
\hline Component & No of experts & Item & Mark \\
\hline \multirow{3}{*}{ IN } & 4 & (IN1,IN2,IN3) & Yes \\
\cline { 2 - 4 } & 1 & (IN1, IN5) & No \\
\hline ED & 5 & (ED1,ED2,ED3,ED4,ED5) & Yes \\
\hline CN & 5 & (CN1,CN2,CN3,CN4,CN5) & Yes \\
\hline PL & 4 & $\begin{array}{l}\text { (PL1,PL3, PL5..PL20, } \\
\text { PL22, PL23, PL25, and } \\
\text { PL27..PL29) }\end{array}$ & Yes \\
& & (PL4,PL24,PL26) & Not sure \\
\cline { 2 - 4 } & 1 & (PL4,PL21) & No \\
\cline { 2 - 4 } & 1 & & \\
\end{tabular}

Overall, the results from the HE were very positive, which indicate that the low fidelity prototype has most of the required educational and enjoyment elements and thus the prototype has good usability. The expert's feedback and comments are discussed in the following section and summarized in Table IV.

\section{A. Experts' Comments and Recommendations}

Four of the five experts gave some suggestions and recommendations, which will be considered when developing the high-fidelity prototype. Two experts suggested changing the interface design colours with lighter colours. One expert suggested adding more storylines regarding women's self-affirmation (self-worth), as well as "what career women would like to achieve".

Another expert suggested that the game has to provide the player with at least two rewards and suggested more sub-games. Two experts recommended changing the use of the bullet style format MCQs in game's quizzes table III summarized the experts' suggestions and comments.
Published By:

Blue Eyes Intelligence Engineering 1986 \& Sciences Publication

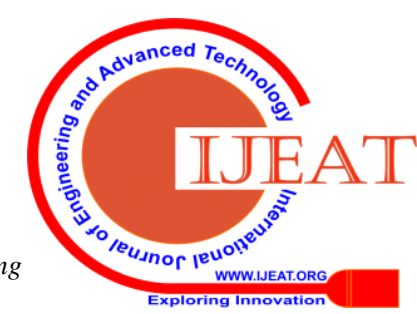


Gender-based Game Engagement Model Validation using Low Fidelity Prototype

Table- IV: Experts' Suggestions and Comment

\begin{tabular}{|c|c|c|c|}
\hline & Item description & Item & Suggestions \& comments \\
\hline \multirow[t]{2}{*}{ IN } & Match between system and real world & IN2 & $\begin{array}{l}\text { The environment or scenery in the game is the same (more scenery needs to } \\
\text { be added to the game). } \\
\text { Suggestion for additional topics in networks such as: } \\
\text { Hardware: crimping new network cables. } \\
\text { Interaction: diagnosing user/system problem. }\end{array}$ \\
\hline & Aesthetic and minimalist design & IN5 & $\begin{array}{l}\text { The interface colour scheme should be lighter to attract player. } \\
\text { There are more dialogue boxes and multiple drops messages in one interface. } \\
\text { Rearrange the order of main menu buttons. }\end{array}$ \\
\hline \multirow[t]{5}{*}{$P L$} & $\begin{array}{l}\text { Control keys follow standard } \\
\text { conventions }\end{array}$ & PL2 & There is a need to change the game quiz-style format to the bullet style MCQs \\
\hline & $\begin{array}{l}\text { Successful users that complete all the } \\
\text { activities in a module should be } \\
\text { rewarded }\end{array}$ & PL4 & $\begin{array}{l}\text { The game has to provide users with at least two rewards, and more sub-games } \\
\text { should be added. }\end{array}$ \\
\hline & $\begin{array}{l}\text { Users feel a sense of control over the } \\
\text { game }\end{array}$ & PL21 & $\begin{array}{l}\text { There is need to play the working game prototype to decide about the player's } \\
\text { immersion in the game. }\end{array}$ \\
\hline & $\begin{array}{l}\text { Users feel emotionally involved in the } \\
\text { game }\end{array}$ & PL24 & Add more storylines regarding women's self-affirmation (self-worth). \\
\hline & $\begin{array}{l}\text { There is an emotional connection } \\
\text { between the player and the game } \\
\text { worlds as well as their "avatar." }\end{array}$ & PL26 & Add more storylines regarding what career women would like to achieve. \\
\hline
\end{tabular}

\section{CONCLUSION}

This paper has presented a study on heuristic evaluation of a serious game low fidelity prototype to validate the game gender-based engagement model. A low fidelity prototype was designed, then the validity and reliability of an adapted $\mathrm{HE}$ questionnaire has been done. Results showed that the questionnaire was valid and reliable. After that, the heuristic evaluation questionnaire was used to evaluate the low fidelity prototype. HE method is used to ensure that the future high fidelity prototype interface design will not have any usability problems. Results from heuristic evaluation showed that the model's constructs have good usability. For future work, high fidelity working prototype will be developed addressing all experts' recommendations and comments.

\section{REFERENCES}

1. D. M. Bressler, A. M. Bodzin, and M. S. Tutwiler, "Engaging middle school students in scientific practice with a collaborative mobile game," J. Comput. Assist. Learn., vol. 35, no. 2, pp. 197-207, 2019.

2. S. Alserri, N. A. M. Zin, and T. S. M. T. Wook, "Gender-based Engagement Model for Designing Serious Games," in The International Conference proceedings on Electrical Engineering and Informatics 2017 (ICEEI2017), 2017, p. 5.

3. O. Dele-Ajayi, J. Shimwell, I. Emembolu, R. Strachan, and M. Peers, "Exploring digital careers, stereotypes and diversity with young people through game design and implementation," in IEEE Globa Engineering Education Conference, EDUCON, 2018, vol. 2018-April, pp. 712-719.

4. C. S. Gonzalez-Gonzalez et al., "Gender and engineering: Developing actions to encourage women in tech," IEEE Glob. Eng. Educ. Conf. EDUCON, vol. 2018-April, no. January 2019, pp. 2082-2087, 2018.

5. A. Hosein, "Girls' video gaming behaviour and undergraduate degree selection: A secondary data analysis approach," Comput. Human Behav., vol. 91, no. September 2018, pp. 226-235, 2019.

6. S.A.Alserri, A. M. Zin, and T.S.M.Wook, "Gender enrolment factors in ict studies," SOFTAM Postgrad. Symp. December, no. December 2016, p. 7, 2017.

Published By:

Blue Eyes Intelligence Engineering

E. Stofan, "Why we need more women in tech by 2030 - and how to do it," World Economic Forum, 2017. [Online]. Available: https://www.weforum.org/agenda/2017/11/women-in-tech-engineerin g-ellen-stofan. [Accessed: 12-Aug-2018].

8. Strachan, A.Peixoto, I.Emembolu, and A. M.T.Restivo, "Addressing the Gender Gap in Engineering and Technology - Exploring Trust and Unconscious Bias_V7," 2018 IEEE Glob. Eng. Educ. Conf., vol. 9974, pp. 2088-2093, 2018.

9. S. Verdugo-Castro, M. C. Sánchez-Gómez, and A. García-Holgado, "Gender gap in the STEM sector in pre and university studies of Europe associated with ethnic factors," in In Proceedings of the Sixth International Conference on Technological Ecosystems for Enhancing Multiculturality (pp. 984-990). ACM., 2018, pp. 984-990.

10. J. Tan and P. L. P. Rau, "A Design of Augmented Tabletop Game Based on RFID Technology," Procedia Manuf., vol. 3, pp. 2142-2148, 2015.

11. B. Pourabdollahian, M. Taisch, and E. Kerga, "Serious games in manufacturing education: Evaluation of," Procedia Comput. Sci., vol. 15, pp. 256-265, 2012.

12. B. Paaben, T. Morgenroth, and M. Stratemeyer, "What is a True Gamer? The Male Gamer Stereotype and the Marginalization of Women in Video Game Culture," Sex Roles, vol. 76, no. 7-8, pp. 421-435, 2017.

13. W. Admiraal, J. Huizenga, I. Heemskerk, E. Kuiper, M. Volman, and G. Ten Dam, "Gender-inclusive game-based learning in secondary education,” Int. J. Incl. Educ., vol. 18, no. 11, pp. 1208-1218, 2014.

14. O. Dele-Ajayi, R. Strachan, J. Sanderson, and A. Pickard, "Designing for All: Exploring Gender Diversity and Engagement with Digital Educational Games by Young People," in FIE 2018 - IEEE Frontiers in Education Conference, 3rd - 6th October 2018, San Jose, California., 2018, p. 6.

15. Z. Khan and B. Kapralos, "A low-fidelity serious game for medical-based cultural competence education," Health Informatics J., p. 146045821771956, 2017.

16. B. Manero, J. Torrente, M. Freire, and B. Fernández-Manjón, “An instrument to build a gamer clustering framework according to gaming preferences and habits," Comput. Human Behav., vol. 62, pp. 353-363, 2016.

17. D. Romrell, "Gender and Gaming: A Literature Review," in In annual meeting of the AECT International Convention, Hyatt Regency Orange County, Anaheim, CA, 2015, no. November, pp. 11-22.

\& Sciences Publication

(C) Copyright: All rights reserved. 
18. L. Vermeulen and J. Van Looy, “'I Play So I Am?’ A Gender Study into Stereotype Perception and Genre Choice of Digital Game Players," J. Broadcast. Electron. Media, vol. 60, no. 2, pp. 286-304, 2016.

19. B. Manero, J. Torrente, C. Fernandez, and B. Fernandez, "Investigating the impact of gaming habits, gender, and age on the effectiveness of an educational video game: An exploratory study," in IEEE Transactions on Learning Technologies, 2016, no. 10(2), pp. 236-246.

20. M. F. Perreault, G. P. Perreault, J. Jenkins, and A. Morrison, "Depictions of Female Protagonists in Digital Games: A Narrative Analysis of 2013 DICE Award-Winning Digital Games," Games Cult., vol. 13, no. 8, pp. 843-860, 2018.

21. S. Chess, N. J. Evans, and J. J. Baines, "What Does a Gamer Look Like? Video Games, Advertising, and Diversity," Telev. New Media, vol. 18, no. 1, pp. 37-57, 2017.

22. E. Adams, "Fundamentals of game design.," in Game design and development, Third Edit., Pearson Education, Inc, 2014, p. 576.

23. J. Osunde, G. Windall, L. Bacon, and L. Mackinnon, “An Investigation Of Digital Games Features That Appeal To Young Females And Males," in In: European conference on games based learning (ECGBL), 8-9 Oct 2015, Norway., 2015, pp. 1-12.

24. G. C. Gardiner, "Influencing middle school girls to study computer science through educational computer games," J. Comput. Sci. Coll., vol. 28, no. 6, pp. 90-97, 2013.

25. S. Alserri, N. A. M. Zin, and T. S. M. T. Wook, "Gender-based Engagement Model for Serious Games," Int. J. Adv. Sci. Eng. Inf. Technol., vol. Vol.8 (201, no. 4, pp. 1-8, 2018.

26. J. Nielsen and R. Molich, "Heuristic Evaluation of user interfaces," $\mathrm{CHI}$ '90 Proc. SIGCHI Conf. Hum. Factors Comput. Syst., no. April, pp. 249-256, 1990.

27. M. Rajanen and D. Rajanen, "Heuristic evaluation in game and gamification development," in CEUR Workshop Proceedings, 2018, vol. 2186, pp. 159-168.

28. A. Omar, H. M., \& Jaafar, "Conceptual framework for a heuristics based methodology for interface evaluation of educational games," in International Conference on Computer Technology and Development 2010, vol. 1, no. 2, pp. 594-598.

29. H. M. Omar and A. Jaafar, "Heuristics evaluation in computer games," CAMP'10, pp. 188-193, 2010.

30. J. Paavilainen, "Critical review on video game evaluation heuristics," in Future Play 2010: Research, Play, Share - International Academic Conference on the Future of Game Design and Technology, 2010, pp. 56-65.

31. M. a Federoff, "Heuristics and usability guidelines for the creation and evaluation of fun in video games," Indiana University, 2002.

32. D. Pinelle, N. Wong, and T. Stach, "Heuristic evaluation for games: usability principles for video game design," Proc. SIGCHI Conf. Hum

33. H. Korhonen and E. M. I. Koivisto, "Playability heuristics for mobile multi-player games," Proc. 2nd Int. Conf. Digit. Interact. media Entertain. arts - DIMEA '07, no. January 2007, p. 28, 2007.

34. G. Hermawati, S. and Lawson, "Establishing usability heuristics for heuristics evaluation in a specific domain: Is there a consensus?," Appl. Ergon., vol. 56, pp. 34-51, 2016.

35. H. Desurvire and C. Wiberg, "Game usability heuristics (PLAY) for evaluating and designing better games: The next iteration," in International Conference on Online Communities and Socia Computing, 2009, vol. 5621 LNCS, pp. 557-566.

36. O. M. Hasiah, Y. Rohana, and J. Azizah, "Quantitative analysis in a heuristic evaluation for usability of Educational Computer Game (UsaECG)," Int. Conf. Inf. Retr. Knowl. Manag. (CAMP), Kuala Lumpur, Malaysia, pp. 187-192, 2012.

37. T. W. Malone, "What makes things fun to learn? heuristics for designing instructional computer games," Proc. 3rd ACM SIGSMALL Symp. first SIGPC Symp. Small Syst. - SIGSMALL '80, vol. 162, pp. 162-169, 1980.

38. S. Soomro, W. F. W. Ahmad, and S. Sulaiman, "Evaluation of Mobile Games Using Playability Heuristics," in International Visua Informatics Conference, 2013, vol. 8034, no. November, pp. 264-274.

39. M. B. Barbosa and A. B. Rêgo, "HEEG: Heuristic Evaluation for Educational Games," in Proceedings of SBGames 2015, 2015, pp. 224-227.

40. A. Omar, H., Yusoff, R. and Jaafar, "Quantitive analysis in a heuristic evaluation for usability of educational computer game (UsaECG)," in Proceedings - 2012 International Conference on Information Retrieval and Knowledge Management, CAMP'12, 2012, pp. 187-192.

41. F-L.Fu, Su.R-C, and A. S-C.Yu, "EGameFlow: A scale to measure learners' enjoyment of e-learning games," Comput. Educ., vol. 52, no. 1, pp. 101-112, 2009.

42. A. Perttula, K. Kiili, A. Lindstedt, and P. Tuomi, "Flow experience in Proc. - 2010 Int. Conf. Inf. Retr. Knowl. Manag. Explor. Invis. World, Factors Comput. Syst., pp. 1453-1462, 2008.

game based learning - a systematic literature review," Int. J. Serious Games, vol. 4, no. 1, pp. 57-72, 2017.

43. P. J. Lavrakas, Encyclopedia of survey research methods. London: Sage Publications, 2008.

\section{AUTHORS PROFILE}

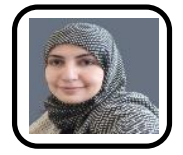

Shahryan Abdulrahman Alserri is member of the faculty at the department of Multimedia and Graphic, Sana'a Community College, Sana'a-Republic of Yemen. Now, she is studying her Ph.D. at Faculty of Information Science \& Technology, Universiti Kebangsaan Malaysia in the field of Multimedia and Usability. She received a M.Sc. from University Putra Malaysia, Faculty of Computer Science and Information Technology in the field of Multimedia. She received a B.Sc. In the field of Computer Science from Saba'a University, Sana'a- Republic of Yemen. She has interest in Educational games, Human Computer Interaction (HCI), electronic learning for her work. She already have published her research articles in many International Conferences, and journals.

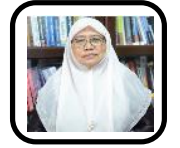

Nor Azan Mat Zin is working as Professor in Research Centre for Software Technology and Management (SOFTAM), Faculty of Information Science and Technology, Universiti Kebangsaan Malaysia. She received her Ph.D. in 2005 from Universiti Kebangsaan Malaysia. She is the Head of Games lab, Multimedia Software and Usability Research Group and area of specialization is Interactive Computing (games, accessibility), Human Computer Interface, and E-Learning Technology.

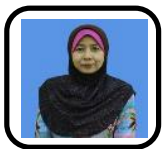

Tengku Siti Meriam Tengku Wook is Senior Lecturer in Software Technology and Management Research Center and Head of Masters Programme Studies at Faculty of Information Science and Technology, National University of Malaysia. Her research focuses on the Human Computer Interaction that include multimedia application, user interaction design and usability, virtual and augmented reality and also e-learning. She has produced more than 20 indexed journals (Quartile / ISI / Scopus). Meanwhile there are 25 ISI and Scopus indexed proceedings, as well as 10 other indexed proceedings. In addition, she has also produced 5 chapters in book. She received Bachelor Degree and Master in Information Technology from National University of Malaysia respectively in 1998 and 1999 and PhD in Human Computer Interaction from University Malaya, Malaysia in year 2012.

Published By:
(C) Copyright: All rights reserved. 